\title{
A 3-D electrical resistivity model beneath the focal zone of the 2008 Iwate-Miyagi Nairiku earthquake (M 7.2)
}

\author{
Hiroshi Ichihara ${ }^{1,2^{*}}$, Shin'ya Sakanaka ${ }^{3}$, Masaaki Mishina ${ }^{4}$, Makoto Uyeshima $^{2}$, Tadashi Nishitani ${ }^{3}$, Yasuo Ogawa $^{5}$, \\ Yusuke Yamaya ${ }^{6}$, Toru Mogi ${ }^{7}$, Kazuhiro Amita ${ }^{3}$ and Takuya Miura ${ }^{3,8}$
}

\begin{abstract}
The 2008 Iwate-Miyagi Nairiku earthquake (M 7.2) was a shallow inland earthquake that occurred in the volcanic front of the northeastern Japan arc. To understand why the earthquake occurred beneath an active volcanic area, in which ductile crust generally impedes fault rupture, we conducted magnetotelluric surveys at 14 stations around the epicentral area 2 months after the earthquake. Based on 56 sets of magnetotelluric impedances measured by the present and previous surveys, we estimated the three-dimensional (3-D) electrical resistivity distribution. The inverted 3-D resistivity model showed a shallow conductive zone beneath the Kitakami Lowland and a few conductive patches beneath active volcanic areas. The shallow conductive zone is interpreted as Tertiary sedimentary rocks. The deeper conductive patches probably relate to volcanic activities and possibly indicate high-temperature anomalies. Aftershocks were distributed mainly in the resistive zone, interpreted as a brittle zone, and not in these conductive areas, interpreted as ductile zones. The size of the brittle zone seems large enough for a fault rupture area capable of generating an M 7-class earthquake, despite the areas distributed among the ductile zones. This interpretation implies that 3-D elastic heterogeneity, due to regional geology and volcanic activities, controls the size of the fault rupture zone. Additionally, the elastic heterogeneities could result in local stress concentration around the earthquake area and cause faulting.
\end{abstract}

Keywords: Magnetotelluric; Iwate-Miyagi earthquake; 3-D resistivity; Inland earthquake

\section{Findings}

\section{Introduction}

The 2008 Iwate-Miyagi Nairiku earthquake (M 7.2) was an inland earthquake that occurred in the vicinity of the volcanic front of the northeastern Japan arc on 14 July 2008. The focal mechanism of the earthquake was a reverse type, which is consistent with the crustal deformation displaying east-west contraction around the study area (Miura et al. 2002, 2004). Aftershocks of the earthquake were distributed within an area of $50 \times 15 \mathrm{~km}$ and showed a complex distribution (Figure 1) (Okada et al. 2012). A curious feature of the earthquake was that

\footnotetext{
* Correspondence: h-ichi@jamstec.go.jp

${ }^{1}$ Research and Development Center for Earthquake and Tsunami, Japan Agency for Marine-Earth Science and Technology, Yokosuka 237-0061, Japan ${ }^{2}$ Earthquake Research Institute, The University of Tokyo, Tokyo 113-0032, Japan

Full list of author information is available at the end of the article
}

volcanic areas (Mt. Kurikoma, Mt. Yakeishi, and Onikobe Caldera) surrounded the earthquake area. In general, ductile areas caused by high temperature and partial melting are distributed beneath volcanic regions. Because these ductile areas impede the propagation of fault ruptures, it would seem difficult for large earthquakes to occur in volcanic regions. To address this question and better understand the relationships between inland earthquakes and volcanic activity, detailed structural investigations are required.

The magnetotelluric (MT) method reveals the distribution of electrical resistivity and has been used to clarify the geology, high-temperature anomalies, and fluid distribution around earthquake zones (e.g., Mitsuhata et al. 2001; Ogawa et al. 2001; Sarma et al. 2004; Unsworth and Bedrosian, 2004; Ichihara et al. 2008, 2009, 2011; Wannamaker et al. 2009; Yoshimura et al. 2009). Mishina (2009) conducted MT surveys along three survey lines 


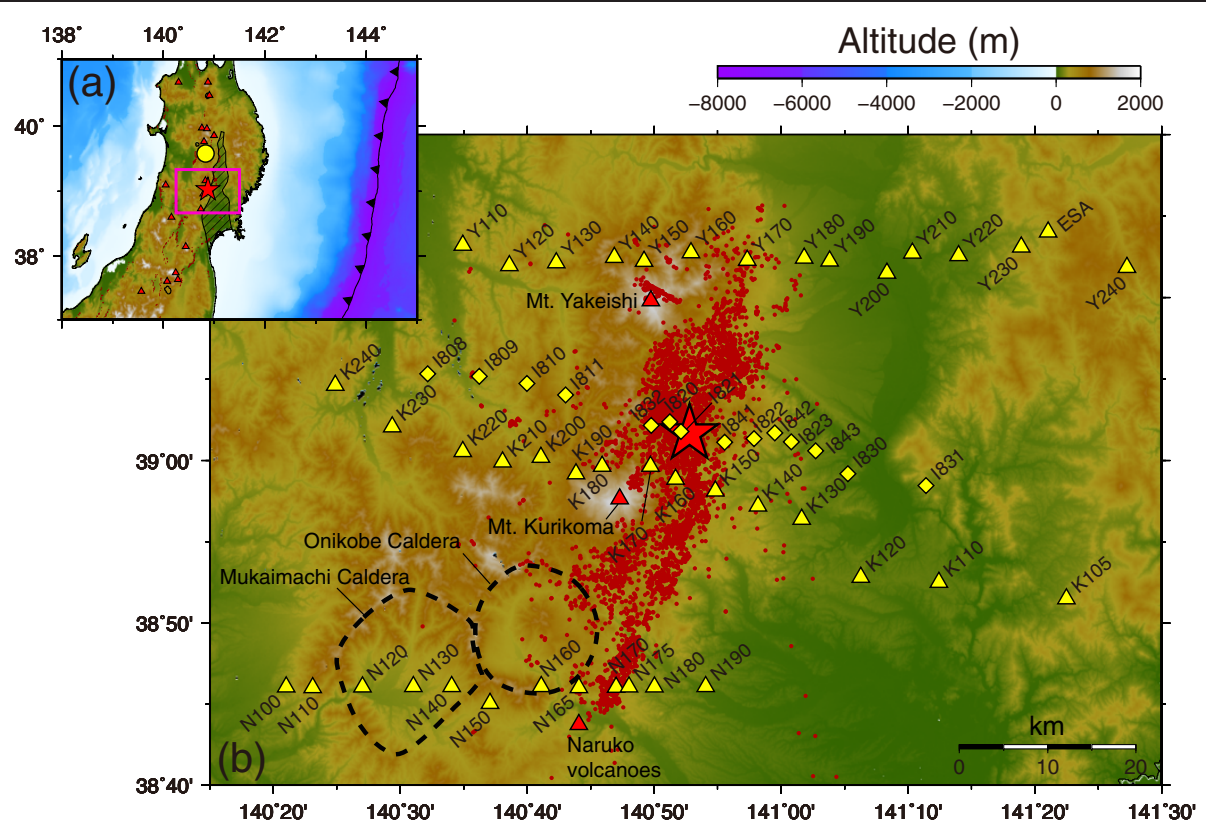

Figure 1 Study locations. The red star and red triangles denote the epicenter of the 2008 Iwate-Miyagi Nairiku earthquake (M 7.2) and active volcanoes, respectively. (a) The yellow circle denotes the remote reference site (Sawauchi station). The cross-hatched area indicates the Kitakami Lowland. (b) Yellow diamonds and triangles denote MT stations in this and a previous study (Mishina 2009), respectively. Small red dots denote aftershocks of the 2008 earthquake (Okada et al. 2012).

across the northern edge, central part, and southern edge of the aftershock area (Figure 1) and estimated resistivity distributions based on two-dimensional (2-D) inversions. The models showed low-resistivity anomalies around the earthquake area that imply crustal fluid flows. They also showed significant differences among the resistivity profiles, which indicate strong three-dimensionality. However, 2-D inversion of a strong three-dimensional (3-D) resistivity structure often results in inaccurate models (e.g., Siripunvaraporn et al. 2005b). Additionally, MT data were not measured around the epicenter of the main shock. In this study, we conducted wide-band MT measurements around the epicentral area and updated the resistivity models based on a 3 -D inversion. Then, we interpreted the geological and thermal heterogeneity based on the estimated resistivity model and discussed the relationship between the earthquake and these heterogeneities.

\section{Magnetotelluric measurements and impedances}

Wide-band MT surveys were conducted at 14 sites along a profile passing through the epicenter of the earthquake in August 2008 (Figure 1). We recorded two horizontal components of electric field and three components of magnetic field using MTU2000 systems (Phoenix Geophysics, Ltd., Toronto, Canada). The electric and magnetic fields were measured using $\mathrm{Pb}-\mathrm{PbCl}_{2}$ electrodes and induction coils, respectively. The recorded time series were converted into frequency-domain MT impedance tensors between 320 and $0.00034 \mathrm{~Hz}$ by using the SSMT200 system
(Phoenix Geophysics, Ltd.). The remote reference technique (Gamble et al. 1979) was applied in the estimation of MT impedances using horizontal magnetic field data from Sawauchi station (Figure 1), which yielded high-quality MT responses.

We then evaluated the dimensionality of the resistivity distribution based on MT impedances and geomagnetic transfer functions at 56 sites: 14 sites evaluated by this study, 41 sites by Mishina (2009), and 1 site by the Geographical Survey Institute. Figure 2 shows the phase tensor ellipses (Caldwell et al. 2004) and Parkinson's induction vectors (Parkinson 1962). The azimuths of $\Phi_{\max }$ $(\alpha-\beta)$ in the phase-tensor ellipses were directed dominantly toward $115^{\circ}$ to $295^{\circ}$ in the long period (227 s in Figure 2). This azimuth is perpendicular to the strike azimuth of the NE Japan arc. On the other hand, no obvious trend was found from the phase tensor in the shorter period or the induction vectors in all periods (Figure 2). Additionally, large $|\beta|$ values $\left(>10^{\circ}\right)$ were recognized in more than half of the phase tensors in the long period. These indicate that the resistivity distribution was highly three-dimensional.

\section{Three-dimensional inversion}

The 3-D resistivity distribution was estimated based on the 56 MT impedances via a 3-D inversion code. We adopted the WSINV3D code (Siripunvaraporn et al. 2005a), which is based on a data-space variant of the Occam approach, for the inversion. Twelve periods of 


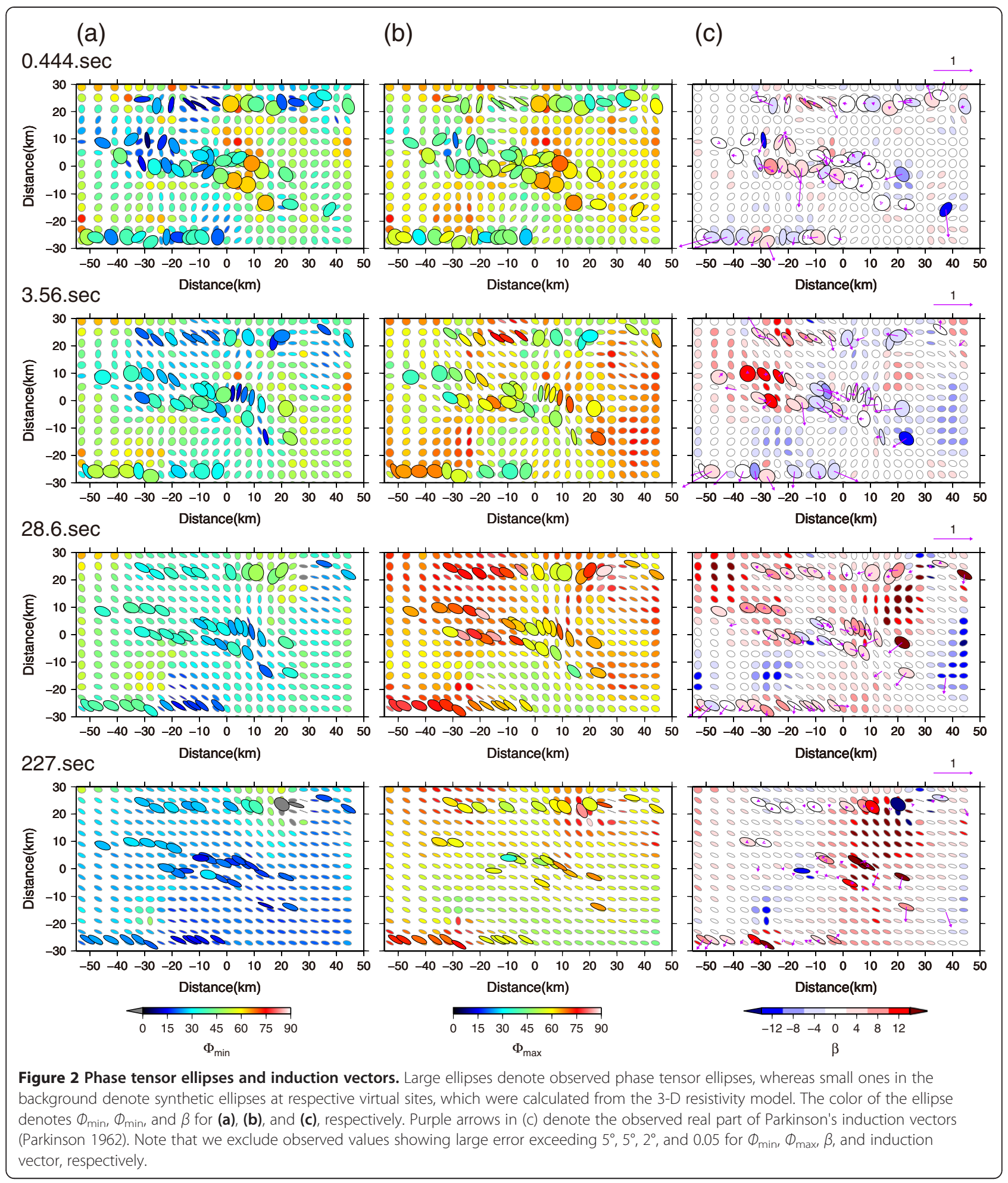

MT impedances between 0.44 and $990 \mathrm{~s}$ were used as input for the inversion. Error floors of $10 \%$ and $20 \%$ were applied for off-diagonal and diagonal components, respectively. The 3-D resistivity model covered a 4,000 $(x$-axis $) \times 4,000 \quad(y$-axis $) \times 1,240 \mathrm{~km} \quad($ vertical $) \quad$ region discretized into $54 \times 65 \times 31$ layers (without air layers). The length and width of the blocks within the survey area were $2 \mathrm{~km}$, but these widened outside the study area. The initial inversion model consisted of a $300 \Omega \mathrm{m}$ homogeneous half-space model, except for the seawater 
area. The model blocks in the seawater area were fixed to $0.3 \Omega \mathrm{m}$. The same model used for the initial model was adapted as a prior model. We iterated the inversion procedure 10 times and obtained a minimum RMS misfit model in the sixth iteration (RMS misfit 2.54). Then, we adopted the sixth iteration model as the initial and prior model and reran the inversion procedures 10 times. Finally, a minimum RMS misfit model was obtained in the second iteration of the second procedure (RMS misfit 1.53). The final inverted resistivity model mostly explained all components of the measured impedances (Figure 3). The model showed distinct conductors around the aftershock area (Figures 4 and 5): a shallow conductor ( 1 to $10 \Omega \mathrm{m}$ ) beneath the Kitakami Lowland $(\mathrm{C}-1)$; conductors beneath the volcanic areas of Mt. Kurikoma (C-2), Onikobe Caldera (C-3a), and Mukaimachi Caldera (C-3b); and conductors distributed beneath the $\mathrm{C}-1$ conductor $(\mathrm{C}-4$ and $\mathrm{C}-5)$. On the other hand, high resistivity (100 to $10,000 \Omega \mathrm{m}$ ) was estimated in the mainshock and aftershock areas.
High $\Phi_{\max }$ and $\Phi_{\min }\left(>45^{\circ}\right)$ in short-period data $(<1 \mathrm{~s})$ in the Kitakami Lowland required the $\mathrm{C}-1$ conductor (Figure 2). Induction vectors around the middle period (1 to $30 \mathrm{~s}$ ) directed to the Kitakami Lowland supported the $\mathrm{C}-1$ conductor. The $\mathrm{C}-2, \mathrm{C}-3 \mathrm{a}, \mathrm{C}-4$, and $\mathrm{C}-5$ conductors were verified based on the following sensitivity tests. If the area enclosed by the black dashed line around $\mathrm{C}-2$ in Figures 4 and 5 was given a uniform resistivity of 300 $\Omega \mathrm{m}$, the RMS misfit for all the MT sites was increased to 1.895 from 1.530 in the inverted model. In this sensitivity test, the calculated phases in the YX component were decreased more than $10^{\circ}$ at site $\mathrm{K} 180$ in the periods between 0.885 and $7.09 \mathrm{~s}$ compared with the measured impedances and the response of the inverted model (Figure 3). Similarly, the sounding curves in the MT sites near the $\mathrm{C}-3 \mathrm{a}, \mathrm{C}-4$, and $\mathrm{C}-5$ conductors and the total RMS misfits were significantly changed when these conductors were replaced with $300 \Omega \mathrm{m}$ (Table 1 and Figure 3). The resistive zone around the earthquake area (R-1) was also verified based on the following

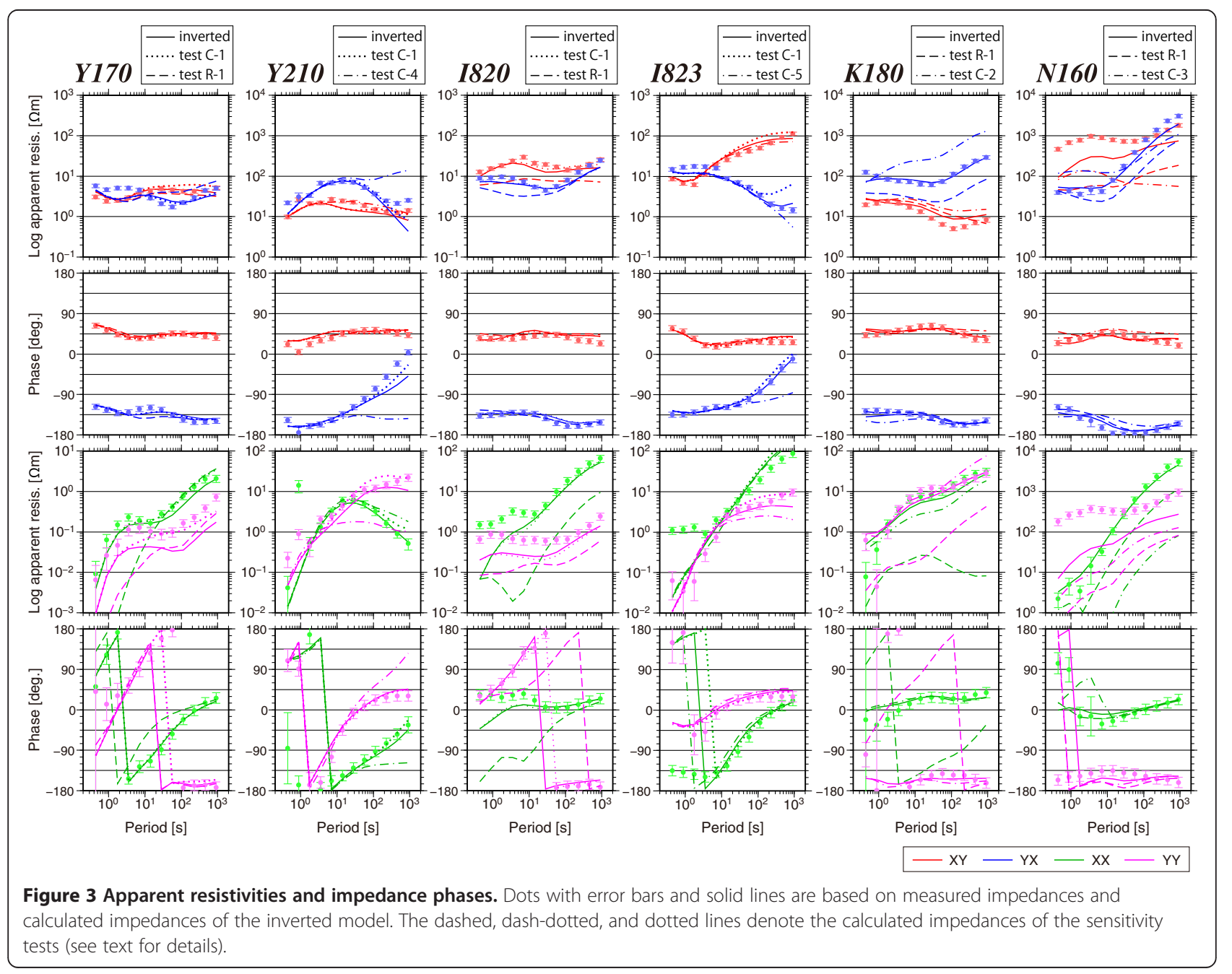



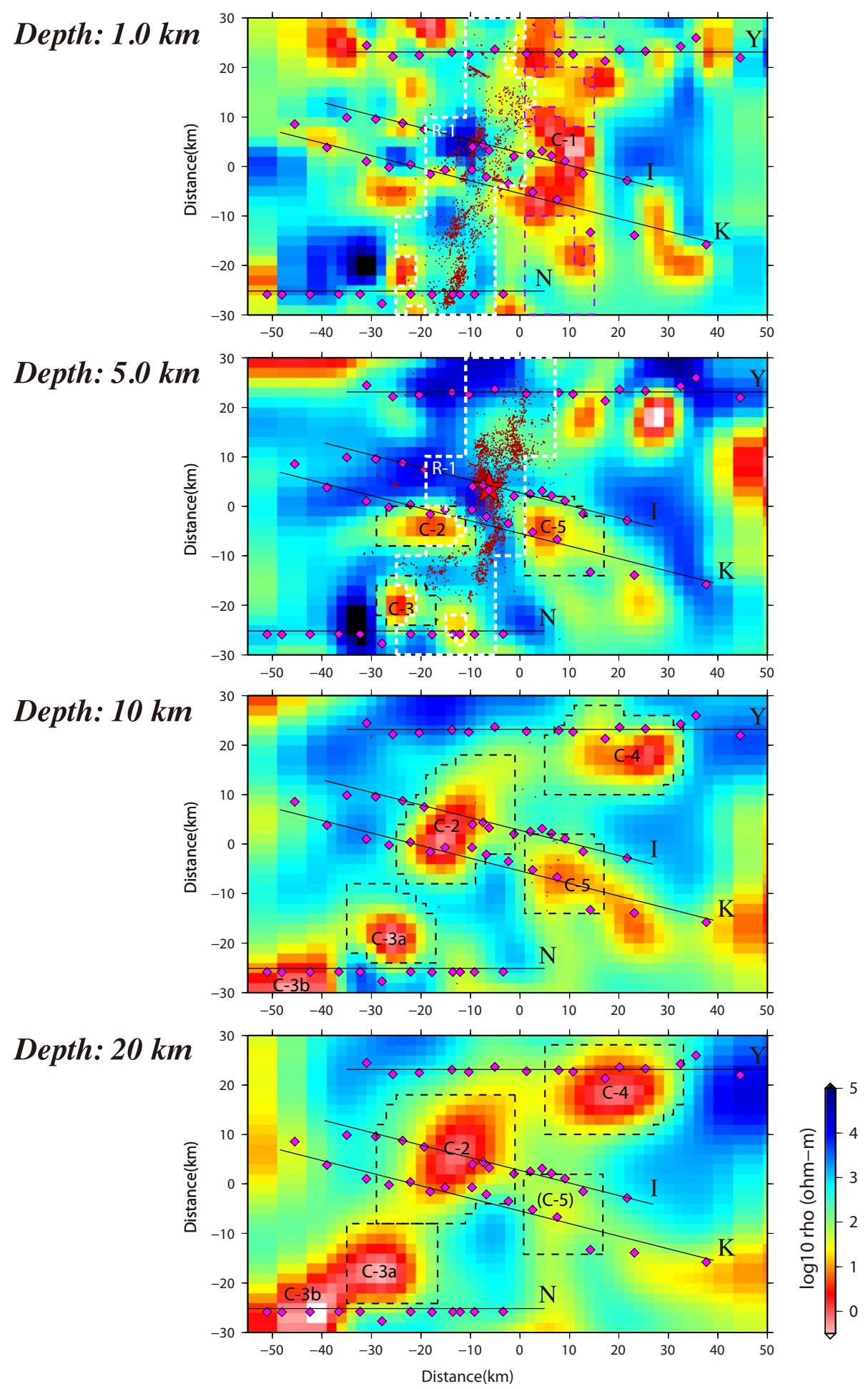

Figure 4 Horizontal cross sections of the inverted resistivity model. The pink diamonds denote MT stations. The red star and red dots denote the epicenters of the mainshock and its aftershocks, respectively. The dashed lines indicate replaced areas in the sensitivity tests. The thin lines denoted as ' $Y$,' 'I,' ' $K$,' and ' $N$ ' indicate the locations of the cross sections in Figure 5. 

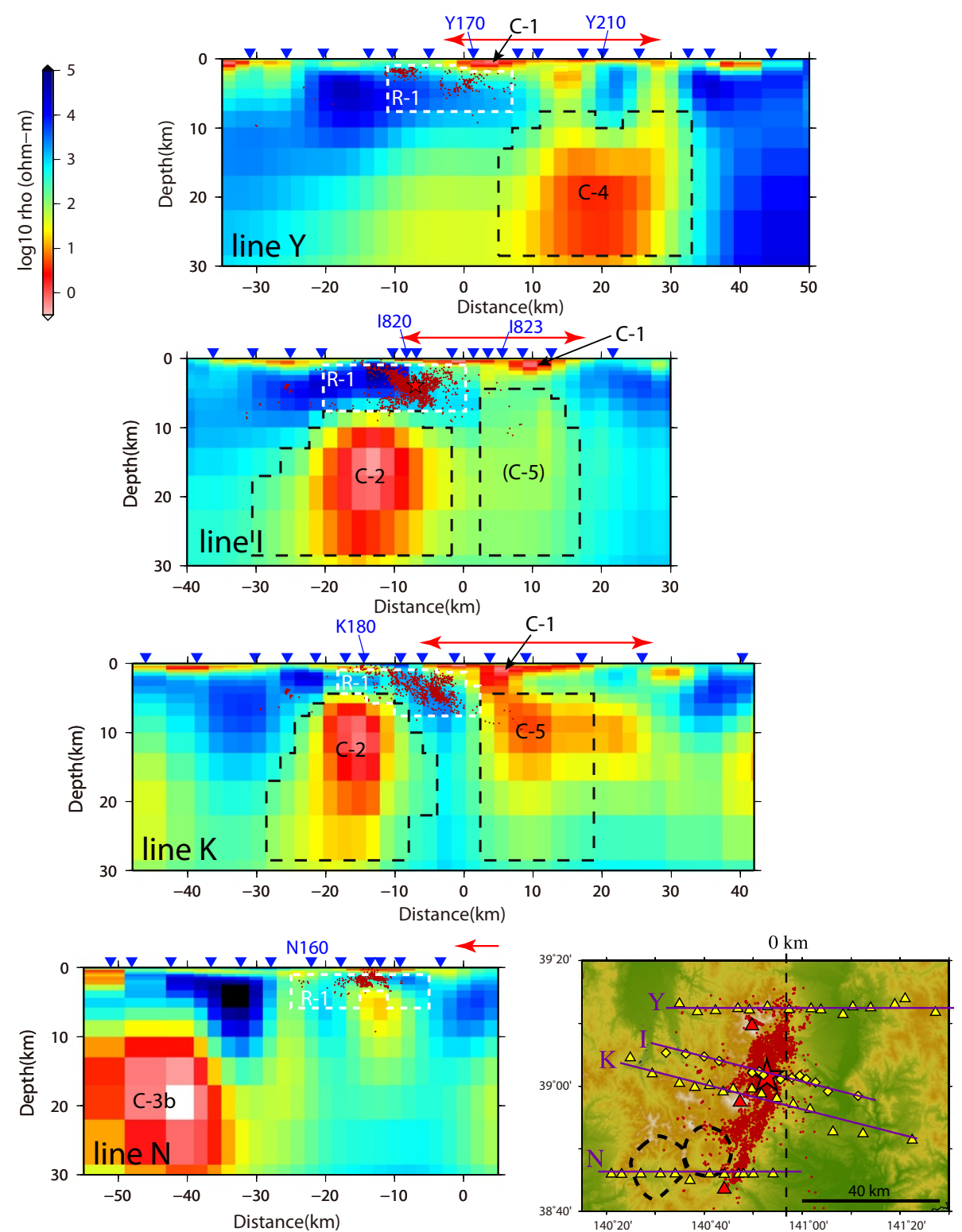

Figure $\mathbf{5}$ Vertical cross sections of the inverted resistivity model. The red arrows indicate the area of the Kitakami Lowland. The other symbols are the same as in Figure 4.

Table 1 The RMS misfits of the sensitivity test models (see text for details)

\begin{tabular}{ccccccc}
\hline Conductor & Inverted model & $\mathbf{3} \boldsymbol{\Omega} \mathbf{~ m}$ & $\mathbf{1 0 \Omega} \mathbf{~}$ & $\mathbf{3 0} \mathbf{\Omega} \mathbf{~}$ & $\mathbf{1 0 0} \boldsymbol{\Omega} \mathbf{~ m}$ & $\mathbf{3 0 0} \boldsymbol{\Omega} \mathbf{~ m}$ \\
\hline $\mathrm{C}-2$ & 1.530 & 1.532 & 1.541 & 1.580 & 1.715 & 1.895 \\
C-3a & 1.530 & 1.537 & 1.568 & 1.667 & 1.895 & 2.118 \\
C-4 & 1.530 & 1.537 & 1.570 & 1.663 & 1.878 & 2.124 \\
C-5 & 1.530 & 1.530 & 1.533 & 1.558 & 1.620 & 1.684 \\
\hline
\end{tabular}

The resistivities in the first row indicate filled resistivities in the tests. RMS misfits indicating significant differences compared with the inverted model are italicized. The significances are based on the $F$ test at the $95 \%$ confidence level. All models have 5,375 degrees of freedom. 
sensitivity test. If the area enclosed by white dashed line in Figures 4 and 5 was given with $30 \Omega \mathrm{m}$, the RMS misfit was increased to 2.906 and the calculated MT impedances were significantly changed in the short-middle period band (<100 s) (Figure 3).

We next constrained the reliable resistivity ranges of the C-2, C-3a, C-4, and C-5 conductors based on the following additional sensitivity tests (Toh et al. 2006). In these tests, we replaced the conductors in the inverted model with 100,30 , and $10 \Omega \mathrm{m}$. The replaced areas are enclosed by dashed lines in Figures 4 and 5, except for the blocks that showed lower resistivity than the replacing resistivities. The RMS misfits of these models are shown in Table 1 . To examine whether the filled test models were significantly different from the original inverted models, we adopted the $F$ test. Based on the $F$ test with a 95\% confidence level, C-2, C-3a, C-4, and C-5 with resistivities higher than $30,30,30$, and 100 $\Omega \mathrm{m}$, respectively, were significantly worse compared with the original inverted model, which indicated that the resistivity of the conductors should be lower than these resistivities.

\section{Discussion}

Although C-1, C-2, C-3b, C-4, and C-5 were also found in the previous study based on the 2-D inversion method (Mishina 2009), their shapes and distribution depths are different in the present model. The C-2 and $\mathrm{C}-3 \mathrm{~b}$ conductors are in shallower areas in the 3-D model than in the 2-D models. This inconsistency is probably due to inaccuracy in the 2-D inversion, because large $|\beta|$ values $\left(>10^{\circ}\right.$ ) above $\mathrm{C}-2$ and $\mathrm{C}-3 \mathrm{~b}$ (Figure 2) indicate a strong 3-D effect in the MT impedances. Additionally, a conductor beneath Mt. Yakeishi in the 2-D model does not occur in the 3-D model. The likely reason for this difference in the models is that the 2-D inversion may have detected $\mathrm{C}-2$, which is distributed alongside but not below the 2-D survey line (Figure 4), because 2-D inversion often shows conductors distributed off the profile (e.g., Siripunvaraporn et al. 2005b).

The C-1 conductor reflects Tertiary sedimentary rocks because these rocks show low resistivity ( 1 to $10 \Omega \mathrm{m}$ ) in the NE Japan area (Takakura 1995; Ichihara et al. 2011) and are distributed from the surface to a depth of 3,000 m (maximum) beneath the Kitakami Lowland, according to geological and seismic surveys (e.g., Kato et al. 2006). However, the $C-1$ conductor is not shown in blank areas of the MT stations (between lines $\mathrm{Y}$ and I and east of line N), although seismic surveys found thick sediment in these areas (Kato et al. 2006). In order to assess the impact of the surface conductive sediment in the blank areas to the present MT data, we filled these areas (purple dashed line in Figure 4, depth 0.5 to $3.0 \mathrm{~km})$ in the inverted model with conductor $(5 \Omega \mathrm{m})$ and calculated MT impedances ('test C-1' in Figure 3). The calculated impedances are slightly changed from these of the inverted model except for the long-period impedances in the eastern part of C-1 area where deep conductors such as $\mathrm{C}-4$ and $\mathrm{C}-5$ also affect the longperiod MT responses as we discuss later. This indicates that the present MT data are hard to detect $\mathrm{C}-1$ in the blank areas, and thus, conductors are possibly distributed. On the other hand, the resistive zone including $\mathrm{R}-1$ beneath $\mathrm{C}-1$ and the aftershock area is reliable regardless of the shape of $\mathrm{C}-1$ conductor because it slightly affects the MT impedances above the R-1 while the MT responses are significantly changed when R-1 is covered with $30 \Omega \mathrm{m}$ (sites Y170 and I820 in Figure 3). The R-1 are interpreted as granites because these rocks are distributed beneath the Tertiary sedimentary rocks and are a basement rock of the NE Japan arc (e.g., Sato 1994).

The C-2 conductor is distributed beneath Mt. Kurikoma, which has displayed Quaternary volcanic activity (Fujinawa et al. 2001). Okada et al. (2010) indicated a low-velocity (Vs) anomaly in this area that was interpreted as partial melting. They inferred that the melt originated from upwelling flow in the mantle wedge (e.g., Hasegawa et al. 2005). Thus, C-2 can be interpreted as high-temperature or partial melt zones related to volcanic activities. Assuming that $\mathrm{C}-2$ consists of a silicic composition and contains 2.5 to $3.0 \mathrm{wt} \%$ or $0 \mathrm{wt} \% \mathrm{H}_{2} \mathrm{O}$, the temperature of $\mathrm{C}-2(<30 \Omega \mathrm{m})$ would be $500^{\circ} \mathrm{C}$ or $600^{\circ} \mathrm{C}$, respectively, based on Gaillard (2004) (Figure 6). Similarly, the temperature of $\mathrm{C}-3 \mathrm{a}(<30 \Omega \mathrm{m})$, which is

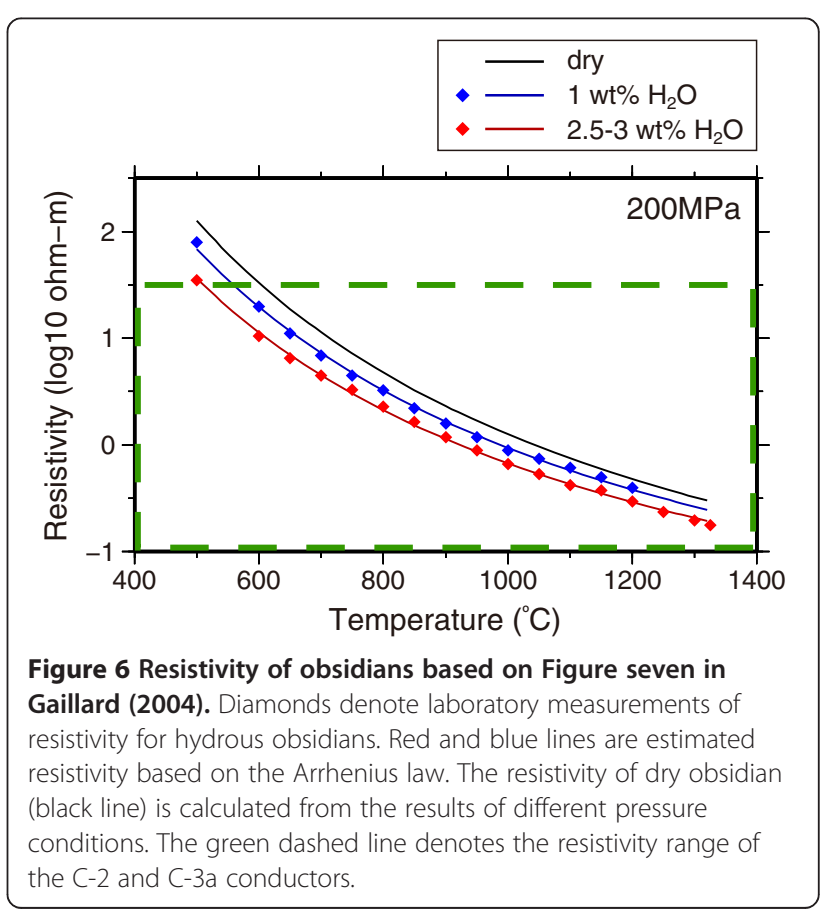


distributed beneath the Onikobe Caldera, should be more than $500^{\circ} \mathrm{C}$. In contrast, the temperature in the nonvolcanic area of the volcanic front area at a depth of $8 \mathrm{~km}$ should be $210^{\circ} \mathrm{C}$, assuming a heat flow of $80 \mathrm{~mW} / \mathrm{m}^{2}$ (based on Tanaka and Ishikawa (2002) and Tanaka et al. (2004)). Therefore, the temperature in the areas of the C-2 and C-3a conductors should be $200^{\circ} \mathrm{C}$ higher than that of the surrounding area, assuming that high temperature causes the conductive anomalies. The actual temperature in the areas of the C-2 and C-3a conductors, however, should be higher than these estimates for the following reasons: (1) andesite, which requires a higher temperature to explain the same resistivity, as compared to silicic material (e.g., Gaillard and Marziano 2005), is distributed in the Kurikoma volcano (Fujinawa et al. 2001) and (2) the actual resistivity in the conductive areas should, in part, be lower than $30 \Omega \mathrm{m}$ because the inverted model shows a value of $1 \Omega \mathrm{m}$ in the centers of the $\mathrm{C}-2$ and $\mathrm{C}-3 \mathrm{a}$ conductors and the inversion adopted a smoothness constraint. Partial melt or a large amount of aqueous fluid may be required to explain such a low resistivity. For better constraint, additional surveys are required, especially for the $\mathrm{C}$-3a conductor, which does not include an MT station.

The C-4 conductor is possibly required to explain outof-quadrant phases in the YX component at sites Y200, Y210, and Y220 because the anomalous large phases are not explained when the C-4 conductor is filled with 300 $\Omega \mathrm{m}$ (Figure 3). Similarly, out-of-quadrant phases observed at site I823 are not explained when C-5 is filled with 300 $\Omega \mathrm{m}$ (Figure 3). On the other hand, strong channeling of telluric current due to the shallow conductor beneath the Kitakami Lowland (C-1) is also a candidate for the anomalous large phases because a shallow conductor complex sometimes induces out-of-quadrant phases (e.g., Ichihara and Mogi 2009; Ichihara et al. 2013). Indeed, the above hypothesis model that the conductor is inserted in the blank areas of the MT sites (Figure 4) increases YX phase in the anomalous phase areas (Figure 3). However, the true resistivity distribution around the Kitakami Lowland is difficult to obtain based on the present data because the shallow resistivity distribution is not constrained in the blank area of MT stations, as we discussed previously.

The aftershocks are dominantly distributed in the resistive zone but are slightly within the $\mathrm{C}-1$ and $\mathrm{C}-2$ conductors. Because these are interpreted as granitic and Tertiary sedimentary rocks and high-temperature areas, respectively, the aftershocks occurred in brittle areas but rarely in ductile areas. This indicates that the seismicity depended highly on three-dimensional elastic heterogeneity. As mentioned in the 'Introduction', the magnitude and rupture area of the 2008 Iwate-Miyagi Nairiku earthquake (M 7.2) are anomalously large for an earthquake occurring in a volcanic area where ductile zones are generally distributed. However, this study has indicated that the ductile zones related to volcanic activities are patchily distributed and that the size of the brittle area is large enough for M 7-class earthquakes to occur. These elastic heterogeneities may also have been responsible for the earthquake occurrence in a different way because elastic heterogeneities may result in local stress concentration zones and can cause faulting (e.g., Ichihara et al. 2008, 2013; Iio et al. 2002). These interpretations imply that the MT method can detect elastic heterogeneities that may control the occurrence and magnitude of the large inland earthquakes. Therefore, three-dimensional resistivity modeling based on MT surveying is important for understanding earthquake occurrences.

\section{Conclusion}

We conducted magnetotelluric surveys at 14 stations around the focal area of the 2008 Iwate-Miyagi Nairiku earthquake (M 7.2). Based on the MT impedances along four profiles by the present and previous studies, a preliminary 3-D resistivity model was obtained using WSINV3D code. The resistivity model showed a shallow conductive zone $(\mathrm{C}-1)$ and a few distinct conductive areas around the focal area (C-2, C-3a, C-4, and C-5). C-1 was interpreted as Tertiary sediment based on its geological distribution. $\mathrm{C}-2$ and $\mathrm{C}-3 \mathrm{a}$ possibly indicate high-temperature zones related to volcanic activities beneath Mt. Kurikoma and Onikobe Caldera. Aftershocks were distributed mainly in the resistive zone and not in the aforementioned conductive zones, which implies that elastic heterogeneity due to volcanic activity and geology may control the magnitude and occurrence frequency of such earthquakes. However, this study could not constrain the precise resistivity distribution in the blank areas of MT stations. Thus, dense surveys between the existing profiles of MT stations are required for more detailed interpretations.

\section{Competing interests}

The authors declare that they have no competing interests.

\section{Authors' contributions}

$\mathrm{HI}$ (corresponding author) participated in the acquisition, analysis, and interpretation of data, and drafted the manuscript. SS, MM, MU, TN, YO, YY, and TM (Toru Mogi) participated in the acquisition and interpretation of data. KA and TM (Takuya Miura) participated in the acquisition of data. All authors read and approved the final manuscript.

\section{Acknowledgements}

We thank the landowners in the study region for their permission to establish observation sites on their land. $\mathrm{H}$. Shinohara of Akita University provided assistance with the data acquisition. The Nittetsu Mining Consultants Co., Ltd. provided us with their continuous geomagnetic records at the Sawauchi station as remote references. The Geographical Survey Institute provided the MT impedance at the Esashi station. Prof. Okada, Graduate School of Science, Tohoku University, provided the seismicity data. Generic Mapping Tools software (Wessel and Smith 1998) was used to draw some of the figures. The manuscript was improved by thoughtful comments from two anonymous reviewers. This research was supported by the Grant-in-Aid 20900001 (Kaken-hi) and the Multidisciplinary Research Project for High Strain Rate Zones of the Ministry of Education, Culture, Sports, Science and Technology (MEXT), Japan. 


\section{Author details}

${ }^{1}$ Research and Development Center for Earthquake and Tsunami, Japan Agency for Marine-Earth Science and Technology, Yokosuka 237-0061, Japan. 2Earthquake Research Institute, The University of Tokyo, Tokyo 113-0032, Japan. ${ }^{3}$ Faculty of International Resource Sciences, Akita University, Akita 010-8502, Japan. ${ }^{4}$ Research Center for Prediction of Earthquakes and Volcanic Eruptions, Graduate School of Science, Tohoku University, Sendai 980-8578, Japan. ${ }^{5}$ Volcanic Fluid Research Center, Tokyo Institute of Technology, Tokyo 152-8551, Japan. ${ }^{6}$ Institute of Geology and Geoinformation, National Institute of Advanced Industrial Science and Technology (AIST), Tsukuba 305-8567, Japan. ${ }^{7}$ Institute of Seismology and Volcanology, Graduate School of Science, Hokkaido University, Sapporo 060-0810, Japan. ${ }^{8}$ Current address: JGI, Inc., Tokyo 112-0012, Japan.

\section{Received: 11 December 2013 Accepted: 26 May 2014} Published: 10 June 2014

\section{References}

Caldwell TG, Bibby HM, Brown C (2004) The magnetotelluric phase tensor. Geophys J Int 158(2):457-469

Fujinawa A, Fujita K, Takahashi M, Umeda K, Hayashi S (2001) Development history of Kurikoma Volcano, Northeast Japan. Bull Volcanological Soc Japan 46:269-284

Gaillard F (2004) Laboratory measurements of electrical conductivity of hydrous and dry silicic melts under pressure. Earth Planet Sci Lett 218(1-2):215-228, doi:10.1016/S0012-821x(03)00639-3

Gaillard F, Marziano Gl (2005) Electrical conductivity of magma in the course of crystallization controlled by their residual liquid composition. J Geophys Res 110(B6), B06204, doi:10.1029/2004jb003282

Gamble TD, Clarke J, Goubau WM (1979) Magnetotellurics with a remote magnetic reference. Geophysics 44(1):53-68

Hasegawa A, Nakajima J, Umino N, Miura S (2005) Deep structure of the northeastern Japan arc and its implications for crustal deformation and shallow seismic activity. Tectonophysics 403(1-4):59-75

Ichihara H, Mogi T (2009) A realistic 3-D resistivity model explaining anomalous large magnetotelluric phases: the L-shaped conductor model. Geophys J Int 179(1):14-17, doi:10.1111/J.1365-246x.2009.04310.X

Ichihara H, Honda R, Mogi T, Hase H, Kamiyama H, Yamaya Y, Ogawa Y (2008) Resistivity structure around the focal area of the 2004 Rumoi-Nanbu earthquake (M 6.1), northern Hokkaido, Japan. Earth Planets Space 60(8):883-888

Ichihara H, Mogi T, Hase H, Watanabe T, Yamaya Y (2009) Resistivity and density modelling in the 1938 Kutcharo earthquake source area along a large caldera boundary. Earth Planets Space 61(3):345-356, doi:10.1016/J. Tecto.2013.05.020

Ichihara H, Uyeshima M, Sakanaka S, Ogawa T, Mishina M, Ogawa Y, Nishitani T, Yamaya Y, Watanabe A, Morita Y, Yoshimura R, Usui Y (2011) A fault-zone conductor beneath a compressional inversion zone, northeastern Honshu, Japan. Geophys Res Lett 38, L09301, doi:10.1029/2011gl047382

Ichihara H, Mogi T, Yamaya Y (2013) Three-dimensional resistivity modelling of a seismogenic area in an oblique subduction zone in the western Kurile arc: constraints from anomalous magnetotelluric phases. Tectonophysics 603:114-122, doi:10.1016/J.Tecto.2013.05.020

lio Y, Sagiya T, Kobayashi Y, Shiozaki I (2002) Water-weakened lower crust and its role in the concentrated deformation in the Japanese Islands. Earth Planet Sci Lett 203(1):245-253

Kato N, Sato H, Umino N (2006) Fault reactivation and active tectonics on the fore-arc side of the back-arc rift system, NE Japan. J Struct Geol 28(11):2011-2022, doi:10.1016/J.Jsg.2006.08.004

Mishina M (2009) Distribution of crustal fluids in Northeast Japan as inferred from resistivity surveys. Gondwana Res 16(3-4):563-571, doi:10.1016/J.Gr.2009.02.005

Mitsuhata Y, Ogawa Y, Mishina M, Kono T, Yokokura T, Uchida T (2001) Electromagnetic heterogeneity of the seismogenic region of 1962 M6.5 northern Miyagi earthquake, northeastern Japan. Geophys Res Lett 28(23):4371-4374

Miura S, Sato T, Tachibana K, Satake Y, Hasegawa A (2002) Strain accumulation in and around Ou Backbone Range, northeastern Japan as observed by a dense GPS network. Earth Planets Space 54(11):1071-1076

Miura S, Sato T, Hasegawa A, Suwa Y, Tachibana K, Yui S (2004) Strain concentration zone along the volcanic front derived by GPS observations in NE Japan arc. Earth Planets Space 56(12):1347-1355
Ogawa Y, Mishina M, Goto T, Satoh H, Oshiman N, Kasaya T, Takahashi Y, Nishitani T, Sakanaka S, Uyeshima M, Takahashi Y, Honkura Y, Matsushima M (2001) Magnetotelluric imaging of fluids in intraplate earthquake zones, NE Japan back arc. Geophys Res Lett 28(19):3741-3744

Okada T, Umino N, Hasegawa A (2010) Deep structure of the Ou mountain range strain concentration zone and the focal area of the 2008 Iwate-Miyagi Nairiku earthquake, NE Japan — seismogenesis related with magma and crustal fluid. Earth Planets Space 62(3):347-352, doi:10.5047/Eps.2009.11.005

Okada T, Umino N, Hasegawa A, Group for the aftershock observations of the Iwate-Miyagi Nairiku Earthquake in 2008 (2012) Hypocenter distribution and heterogeneous seismic velocity structure in and around the focal area of the 2008 Iwate-Miyagi Nairiku Earthquake, NE Japan—possible seismological evidence for a fluid driven compressional inversion earthquake. Earth Planets Space 64(9):717-728, doi:10.5047/Eps.2012.03.005

Parkinson WD (1962) The influence of continents and oceans on geomagnetic variations. Geophys J Roy Astr S 6(4):441-449

Sarma SVS, Prasanta B, Patro K, Harinarayana T, Veeraswamy K, Sastry RS, Sarma MVC (2004) A magnetotelluric (MT) study across the Koyna seismic zone, western India: evidence for block structure. Phys Earth Planet Inter 142(1-2):23-36, doi:10.1016/J.Pepi.2003.12.005

Sato H (1994) The relationship between Late Cenozoic tectonic events and stress-field and basin development in northeast Japan. J Geophys Res 99(B11):22261-22274

Siripunvaraporn W, Egbert G, Lenbury Y, Uyeshima M (2005a) Three-dimensional magnetotelluric inversion: data-space method. Phys Earth Planet Inter 150(1-3):3-14

Siripunvaraporn W, Egbert G, Uyeshima M (2005b) Interpretation of two-dimensional magnetotelluric profile data with three-dimensional inversion: synthetic examples. Geophys J Int 160(3):804-814

Takakura S (1995) Resistivity of Neogene rocks on the Niigata and the Akita oil fields, Japan. Butsuri-Tansa 48:161-175 (in Japanese with English abstract)

Tanaka A, Ishikawa Y (2002) Temperature distribution and focal depth in the crust of the northeastern Japan. Earth Planets Space 54(11):1109-1113

Tanaka A, Yamano M, Yano Y, Sawada M (2004) Digital Geoscience Map P-5: geothermal gradient and heat flow data in and around Japan. Chishitsu News 603:42-45

Toh H, Baba K, Ichiki M, Motobayashi T, Ogawa Y, Mishina M, Takahashi I (2006) Two-dimensional electrical section beneath the eastern margin of Japan Sea. Geophys Res Lett 33(22), L22309, doi:10.1029/2006GL027435

Unsworth M, Bedrosian PA (2004) Electrical resistivity structure at the SAFOD site from magnetotelluric exploration. Geophys Res Lett 31:L12S05, doi:10.1029/2003GL019405

Wannamaker PE, Caldwell TG, Jiracek GR, Maris V, Hill GJ, Ogawa Y, Bibby HM, Bennie SL, Heise W (2009) Fluid and deformation regime of an advancing subduction system at Marlborough, New Zealand. Nature 460(7256):733-U790, doi:10.1038/Nature08204

Wessel P, Smith WHF (1998) New, improved version of the Generic Mapping Tools released. EOS Trans AGU 79:579

Yoshimura R, Oshiman N, Uyeshima M, Toh H, Uto T, Kanezaki H, Mochido Y, Aizawa K, Ogawa Y, Nishitani T, Sakanaka S, Mishina M, Satoh H, Goto T, Kasaya T, Yamaguchi S, Murakami H, Mogi T, Yamaya Y, Harada M, Shiozaki I, Honkura Y, Koyama S, Nakao S, Wada Y, Fujita Y (2009) Magnetotelluric transect across the Niigata-Kobe Tectonic Zone, central Japan: a clear correlation between strain accumulation and resistivity structure. Geophys Res Lett 36, L20311, doi:10.1029/2009gl040016

\section{doi:10.1186/1880-5981-66-50}

Cite this article as: Ichihara et al:: A 3-D electrical resistivity model beneath the focal zone of the 2008 Iwate-Miyagi Nairiku earthquake (M 7.2). Earth, Planets and Space 2014 66:50. 